\title{
Ventilator Associated Tracheobronchitis: Incidence, Etiology, Predisposing Risk Factors and Drug Resistance
}

\author{
K.S. Mayuri* \\ Sagar Hospitals, Banashakari, Shavige Malleshwara Hills, Kumarswamy Layout, \\ DSI Campus, Bangalore- 560078, India \\ *Corresponding author
}

\section{A B S T R A C T}

Ventilator-associated tracheobronchitis (VAT) is common in incubated patients and is associated with increased morbidity, mortality, and health-care costs. Ventilatorassociated tracheobronchitis (VAT) has been proposed as an intermediate condition between simple colonization of the upper airways and VAP. The present study is undertaken to determine incidence, bacterial etiology, predisposing risk factors and

\section{Keywords}

Ventilator

associated tracheobronchitis,

Mechanical ventilation, Endotracheal aspirates.

\section{Article Info}

\section{Accepted:} 29 June 2017 Available Online: 10 July 2017 antibiotic sensitivity pattern of Ventilator associated tracheobronchitis, in patients admitted to ICU of S.S. Institute of Medical Sciences and Research Centre. Consecutive non duplicated endotracheal aspirate cultures from 365 patients on ventilator for more than 48 hours were included in the present study. VAT was diagnosed with standard criteria with a colony count of more than $10^{6} \mathrm{cfu} / \mathrm{ml}$ of endotrahceal aspirate. Only first episodes of VAT were included in the study. Endotracheal aspirates collected were subjected to gram stain and culture. Culture was performed by quantitative culture technique. Growth on the culture plate was identified by standard microbiological techniques and subjected to antibiotic sensitivity by Kirby Bauer disc diffusion method and CLSI guidelines. Among the 365 cases enrolled to different ICUs 61 patients were diagnosed to have VAT based on standard criteria. The incidence of VAT in the present study was reported to be $16.7 \%$. It was verified that $9.8 \%$ of the patients had polymicrobial infection. Gram negative bacilli showed up as the most common pathogens overall. Most common pathogens isolated were $P$. aeruginosa (29\%) and K. pneumoniae (26\%). Previous imipenem therapy, COPD, CCF, diabetes mellitus, hypertension were found to be important risk factors for VAT. Piperacillin+tazobactum and ceftriaxone+ sulbactam were the antibiotics with high susceptibility rates to common VAT pathogens. High resistance was seen with cefotaxime, ceftriaxone and gentamicin. Pseudomonas aeruginosa was the predominant ES $\beta$ L (36\%) and $\mathrm{M} \beta \mathrm{L}(44 \%)$ producer. Klebsiella pneumoniae (40\%) was predominant AmpC producer.62.5\% of Staphylococcus aureus were resistant to methicillin. VAT is common in mechanically ventilated intensive care unit patients. VAT is associated with longer durations of intensive care unit stay and mechanical ventilation. VAT is frequently caused by MDR organisms. Prophylactic or indiscriminate use of antibiotics should be discouraged for VAT.

\section{Introduction}

Mechanical ventilation (MV) is potentially life saving but it also carries significant risks and complications. Of these is the nosocomial lower respiratory tract infections in intubated 
patients which includes ventilator-associated tracheobronchitis (VAT) and ventilatorassociated pneumonia (VAP) (Melsen et al., 2013). VAT is probably an intermediate process between lower respiratory tract colonization and VAP. Although recent data suggests that VAT may be a separate entity that may contribute to increased length of ICU stay and longer duration of MV (Martin et al., 2010). Both VAP and VAT are clinically characterized by presence of fever, mucopurulent bronchial secretions and leukocytosis. In contrast to VAP, VAT does not involve the pulmonary parenchyma, and as a result does not cause radiographic pulmonary infiltrates (Martin et al., 2010). Incidence of VAT varies between different hospitals and in different ICU's of the same hospital. An incidence of $15.5 \%$ was observed, with VAT as the third most common nosocomial infection after nosocomial pneumonia $(47 \%)$ and urinary tract infection (26\%) (Malacarne et al., 2008).

VAT infection is associated with higher length of ICU stay, duration of mechanical ventilation and mortality rate, resulting in possible weaning difficulties and subsequently leading to VAP in mechanically ventilated ICU patients (Nseir et al., 2002). Hence, this study is conducted to determine the incidence, the causing organisms and predisposing risk factors of VAT.

\section{Materials and Methods}

\section{Source of data}

The data was collected from all consecutive patients admitted in different ICU's on ventilator for more than 48 hours with clinically suspected VAT at S.S. Institute of Medical Sciences and Research Centre. The study was approved by the institutional ethical clearance committee.

\section{Study duration}

A prospective observational study was carried out for duration of two years.

\section{Case definition}

Ventilator associated tracheobronchitis (Nseir et al., 2002)

Ventilator associated tracheobronchitis is defined using all of the following criteria: fever $\left(>38^{\circ} \mathrm{C}\right)$ with no other recognizable cause, new or increased sputum production, positive $\left(\geq 10^{6}\right.$ colony-forming units $/ \mathrm{ml}$ ) endotracheal aspirate culture and no radiographic evidence of nosocomial pneumonia at the time of specimen collection.

\section{Inclusion creteria}

All consecutive non-duplicated patients on ventilator for more than 48 hours with clinically suspected VAT confirmed by radiological findings (Nseir et al., 2002).

\section{Exclusion criteria}

1. Ventilator associated tracheobronchitis with non bacterial etiological agents and anaerobic bacteria.

2. Patients receiving noninvasive pressure ventilation and patients with tracheostomy on ICU admission.

3. VAT preceded by Ventilator associated pneumonia [VAP].

4. Second episode of VAT in the same patient.

5. Clinically suspected VAT cases without the report of bed side portable chest X-ray (Valencia et al., 2003).

6. Clinically suspected VAT cases with features suggestive of lung consolidation (by Chest $\mathrm{X}$ ray report)at the time of admission to ICU ( Torres et al., 2005). 


\section{Method of collection of data}

\section{Specimen collection}

All consecutive non-duplicated Endotracheal Aspirate [ETA] specimens were collected and were sent to microbiology laboratory as per standard guidelines (Collee et al., 2006).

\section{Collection of Endotracheal Aspirate (ETA)}

Endotracheal aspiration (EA) was performed using a sterile catheter with a specimen trap kit, Mucus extractor (Ramsons scientific and surgical industries Pvt. Ltd., Agra, India) after 2-3 minutes of chest physiotherapy. The suction tube was blindly introduced through the endotracheal tube and was wedged into the tracheobronchial tree before aspiration of endotracheal secretions. After the suction the mucus trap with ETA was cut and sent to the microbiology laboratory with aseptic precautions for gram stain and culture.

\section{Specimen processing and quantitative} culture (Goel et al., 2012)

Endotracheal aspirate was homogenized by vortexing for $1 \mathrm{~min}$ followed by centrifugation at $3000 \mathrm{rpm}$ for $10 \mathrm{~min} .1 \mathrm{ml}$ of sample was diluted in $9 \mathrm{ml}$ of $0.9 \%$ sterile saline (1 in 10) and other suitable dilutions was used for quantitative culture. The specimen was plated on sheep blood agar (SBA) (Microxpress, Tulip Diagnostics (P) LTD, Goa, India) and MacConkey agar (Microxpress, Tulip Diagnostics (P) LTD, Goa, India) by using Nichrome wire loop with internal diameter of $4 \mathrm{~mm}$, which holds 0.01 $\mathrm{ml}$ of homogenized ETA secretions. Both plates were incubated overnight at $37^{\circ} \mathrm{C}$ for $16-18$ hours. Threshold of bacterial counts $\geq 10^{6} \mathrm{cfu} / \mathrm{ml}$ for quantitative cultures from ETA secretions were considered for diagnosis of VAT. Growth of any aerobic and facultative anaerobic bacteria below the threshold $\left(\leq 10^{6} \mathrm{cfu} / \mathrm{ml}\right)$ was considered as colonizer or contaminant. Bacterial were identified by standard microbial techniques. The antimicrobial susceptibility testing was performed by Kirby Bauer disc diffusion method according to the criteria put forward by Clinical Laboratory Standards Institute (CLSI). Suspected extended spectrum beta lactamse (ESBL's) producing organisms were confirmed by double disc synergy test. Detection of plasmid mediated AmpC was done by the AmpC disc test and isolates showing reduced susceptibility to Carbapenems (Imepenem and Meropenem) were selected for detection of metallobetalactamase (MBL's) enzyme Imepenem EDTA disc method. MRSA was detected by using Cephoxitin disc by disc diffusion method. For the quality control of the disc diffusion tests ATCC control strains of Escherichia coli ATCC 25922, Staphylococcus aureus ATCC 25923 and Pseudomonas aeruginosa ATCC 27853 strains were used. Predisposing risk factors for VAT were recorded from case sheets and by enquiring with the treating doctors.

\section{Statistical analysis}

Data has been shown in terms of numbers and percentages, and has been analyzed by Chisquare test/ Fisher exact test using Microsoft Office Excel Worksheets.

\section{Results and Discussion}

A total of 365 patients who were on mechanical ventilation for more than $48 \mathrm{hrs}$ were included in the study. Out of which 61 $(16.7 \%)$ patients were confirmed with diagnosis of VAT based on standard criteria with the colony count of more than $10^{6} \mathrm{cfu} / \mathrm{ml}$. $145(39.72 \%)$ patients were observed to have colonization of lower respiratory tract and $159(43.56 \%)$ patients were diagnosed to have VAP (Table 1, Chart 1). Among 61 cases of VAT $42(69 \%)$ were male patients and 19 (31\%) were female patients (Table 2). The 
commonest age group studied was below $1 \mathrm{yr}$ accounting for $21 \%$ of patients, $18 \%$ of patients belonged to the age group of $>60 \mathrm{yrs} .13 \%$ were in the age group between 11-20 yrs and 51-60 yrs (Table 3). In our study out of 61 patients of VAT, $18 \%$ were admitted in SICU, $17 \%$ in MICU. $18 \%$ in NICU, $15 \%$ in CCU and 10\% in PICU, hence it suggests that incidence of VAT cases are highest in SICU and MICU (Table 4). The most frequent cause of ICU admission was closed head injury as a result of road traffic accident next being cases of birth asphyxia and poisoning mainly with organophosporous (Table 5).

Pseudomonas aeruginosa was the most common pathogenic isolates from endotracheal aspirate cultured during 10-11 days following the intubation. Klebsiella pneumonia was predominantly isolated during 6-7 days and 8-9 days following the intubation. Most of the Acinetobacter baumannii isolates were recovered during 1213 days of mechanical ventilation. Whereas, E. coli and Staphylococcus aureus were isolated during the initial 2-5 days of mechanical ventilation (Table 6). The association of predisposing risk factors with VAT was done in our study. It was found there was higher occurrence of VAT was observed among patients on prior imipenem therapy, COPD and in patients who had medical illness like diabetes mellitus, hypertension and CCF. But they were not found to be statistically significant (Table 7).

Most cases of VAT were caused by Gramnegative bacteria, which accounted for $88 \%$ of causative organisms and Gram positive being $12 \%$. Pseudomonas aeruginosa (29\%) and Klebsiella pneumoniae (26\%) were the most common Gram-negative bacteria associated with VAT and among gram positive bacteria Staphylococcus aureus (12\%) was the commonest. Other isolates are Acinetobacter baumannii (20\%), E. coli (8\%),
Citrobacter freundii (6\%). 9.8\% of VAT cases had polymicrobial infection (Table 8 Chart 6). Antimicrobial susceptibility pattern of gram negative bacteria revealed that more than $90 \%$ of the isolates were resistant for 3 different groups of antibiotics. Pseudomonas aeruginosa showed resistance to most of the antibiotics like ceftazidime (84.2\%), cefaperazone $(73.7 \%)$, ceftriaxone $(78.7 \%)$, gentamicin $(68.4 \%)$ and ofloxacin $(94.7 \%)$. The most effective drug of choice for treatment of VAT in Pseudomonas aeruginosa was piperacillin+ tazobactam $(42.1 \%)$ and ceftriaxone+sulbactam $(36.8 \%)$. When Klebsiella pneumoniae was considered, they were found to be resistant to ofloxacin $(88.2 \%)$, ceftazidime $(70.6 \%)$, cefaperazone (94\%) and ceftriaxone (88.2\%). The most effective drug of choice for treatment of VAT in Klebsiella pneumoniae were ceftriaxone+sulbactam (58.8\%), sparfloxacin $(58.8 \%)$ and meropenem (58.8\%). Acinetobacter baumannii showed resistance to ceftazidime $(100 \%)$, gentamicin $(100 \%)$, ofloxacin $(92.3 \%)$. It was sensitive to piperacillin+ tazobactam (46.2\%), ceftriaxone+ sulbactam (53.8\%) and meropenem (30.8\%). Staphylococcus aureus showed sensitivity to linezolid (75\%), azithromycin $(62.5 \%)$ clindamycin $(62.5 \%)$ and vancomycin (100\%). Resistance to penicillin $(87.5 \%)$ and ciprofloxacin $(87.5 \%)$ (Tables 9 and 10). Most of the bacterial isolate from VAT patients were resistant to two or more antibiotics.78.7\% isolates in the present study were multi drug resistant. Among the 58 gram negative bacteria isolates of VAT, $76 \%$ were extended spectrum beta lactamases producers, 26\% were AmpC producers and $43 \%$ were $\mathrm{M} \beta \mathrm{L}$ producers. Pseudomonas aeruginosa was the predominant ES $\beta \mathrm{L}(36 \%)$ and $\mathrm{M} \beta \mathrm{L}(44 \%)$ producer. Klebsiella pneumoniae (40\%) was predominant AmpC producer. Among 8 Staphylococcus aureus isolated $62.5 \%$ of strains were Methicillin Resistant 
Staphylococcus aureus (Table 11).

The present study is a prospective study carried over a period of 2 year, which included 365 patients requiring mechanical ventilation for more than 48 hours and in these patient's the incidence, etiology, predisposing risk factors and screening of drug resistance are analyzed.

The incidence of VAT in the present study is $16.7 \%$. The incidence in different study varied from $4 \%$ to $17.8 \%$. The incidence was4\%in the study by Vincet $e t$ al., (Vincent et al., 1995) form Europe in 1995, 17.8\% as observed by Richards et al., (Richards et al., 1999) from Unites States in the year 1999. $10.6 \%$ as observed by Nseir et al., in France in 2002 .

The incidence of VAT in the present study correlates with the other studies. But there is a wide variation in the incidence of VAT in different studies. This difference could be mainly due to the different methods used for the diagnosis, sample size and underlying disease state requiring the ventilation.

In our study out of 61 cases of VAT 42(69\%) were male patients and 19 were female patients (19\%). Incidence of VAT was found to be more in male patients than in female patients as same as in other studies done by Lipovy and Rihová et al., (2011) were in 31 (9\%) were female patients and $96(27.5 \%)$ were male patients out of 348 cases admitted to ICU's, where as in a study conducted by Dallas et al., (2011) showed no sex predilection to VAT. In the present study the distribution of VAT was found to be more in the age group below 1 year and $>60$ yrs which was found to be similar to study conducted by Nseir et al., (2002) Incidence being higher in age group of $>60 \mathrm{yrs}$ can be explained on the basis of impairment of systemic defenses in these patients which predisposes for respiratory tract colonization by Gram-negative bacilli. Factors predisposing to colonization are impairment of mucosal clearance and loss of mucosal integrity. In our study the incidence of VAT is found to be higher in the surgical ICU's which is similar to other studies conducted by Sadek et al., (2014) and Nseir et al., (2011). In contrary, study conducted by Dallas et al., (2011) reported that incidence of VAT was similar in surgical and medical ICU patients.

In the present study Pseudomonas aeruginosa was the most common pathogenic isolates from endotracheal aspirate cultured during 10-11 days following the intubation. Klebsiella pneumoniae was predominantly isolated during 6-7 days and 8-9 days following the intubation. Most of the Acinetobacter baumannii isolates were recovered during 12-13 days of mechanical ventilation. Increasing numbers of lower respiratory tract pathogens over time following intubation are likely to be a sign of increased bacterial virulence, greater inflammation and risk of progression from colonization to VAT (Nseir et al., 2008).

In our study close association was found to be prior imipenem therapy, COPD, CCF, diabetes mellitus, hypertension as risk factors for the development of VAT, but they could not be proven statistically. According to Nseir et al., (2013) he observed in his study that there was significant association between VAT and prior antibiotic therapy and COPD. Patients with COPD might be diagnosed more frequently with VAT as they are more likely to produce larger quantities of purulent secretions and may be more likely to have bacterial colonization of their upper airways. Most common pathogens of VAT in the present study were $P$. aeruginosa and $K$. pneumoniae. Nseir et al., (2002) have reported $P$. aeruginosa as a most common pathogen of VAT. Other common pathogens of VAT as reported by Nseir et al., were A. baumannii and K. pneumoniae Dallas et al., 
(2011) reported Acinetobacter baumannii as the most common pathogen of VAT followed by that is the Pseudomonas aeruginosa and Klebsiella species. Other organisms isolated in our study are Acinetobacter baumannii, E. coli, Citrobacter freundii and Staphylococcus aureus. In our study $9.8 \%$ of VAT cases were found to be polymicrobial which is similar to the studies conducted by Dallas et al., and Bouza et al., (2013) which was found to be $7 \%$ and $9.8 \%$ respectively.

Most of the pathogens isolated in our study were observed to be multi drug resistant. High degree of resistance of VAT pathogens to cefotaxime, ceftriaxone, gentamicin and ceftazidme was observed in the present study. This may be due to frequent use of this broad spectrum antibiotic for prophylaxis of ventilator associated infections at our ICU's. Though piperacillin in combination with tazobactam and ceftriaxone + sulbactam retained good susceptibility, majority of the VAT pathogens were found to be resistant to most of the other antibiotics. Prevalence of high rate of drug resistance was also observed in the study conducted by Nseir et al., (2002) he suggested that the high rate of antimicrobial-resistant bacteria may be related to the great number of patients transferred from another ward or treated by antibiotics before ICU admission, as well as to the longer duration of stay in ICU because of the underlying disease itself. The exposure to antibiotics is a significant risk factor for colonization and infection with nosocomial MDR pathogens has been observed by many authors. Hence, this emphasizes the need for judicious selection of patients for antibiotic therapy. In the present study, systemic antibiotics were frequently administered to VAT patients under the guidance of physicians, in short courses followed by deescalation. Antibiotic treatment in the present study witnessed lower rates of clinical signs and symptoms, faster weaning followed by extubation, Nseir et al., (2008) conducted a randomized, controlled, multicentric study on antimicrobial treatment for ventilator associated tracheobronchitis. And the study suggested that patients with VAT, compared with matched control subjects, had significantly lower median duration of mechanical ventilation and longer duration of ICU stay in patient treated with appropriate antibiotics, but antibiotic therapy did not appear to protect against VAP.

Palmer et al., (2008) performed a randomized blinded placebo-controlled trial to determine the impact of aerosolized antibiotics on outcomes in patients with VAT. Aerosolized antibiotics were found to be associated with significantly lower rates of VAP at the end of treatment, reduced usage of systemic antibiotics and increased weaning. Interestingly, lower rates of antimicrobial resistance were also found in patients treated with aerosolized antibiotics.

Overuse of antibiotic therapy for patients with pulmonary infiltrates in the ICU has been demonstrated to be associated with higher costs, antimicrobial resistance and superinfections, without decreasing the length of stay or mortality rate (Cunnion et al., 1996). Several investigators have found a close association between previous use of antibiotics and the emergence of subsequent antibiotic resistance in both Gram- negative and Gram-positive bacteria (Edmond et al., 1995; Husni et al., 1999). Further studies are necessary to determine whether antibiotic medication for mechanically ventilated patients with VAT could improve their outcomes. $\beta$-Lactamases are the commonest cause of bacterial resistance to $\beta$-lactam antimicrobial agents. In our study $76 \%$ were extended spectrum beta lactamases producers, $26 \%$ were AmpC producers and $43 \%$ were $\mathrm{M} \beta \mathrm{L}$ producers. Pseudomonas aeruginosa was the predominant ES $\beta \mathrm{L}(36 \%)$ and $\mathrm{M} \beta \mathrm{L}$ (44\%) producer which were similar to the study conducted by Lee et al., (Lee et al., 
Int.J.Curr.Microbiol.App.Sci (2017) 6(7): 3864-3879

2003). 
Table.1 Incidence of VAT

\begin{tabular}{|l|c|}
\hline Patients & Number \\
\hline Colonizer & $145(39.72 \%)$ \\
\hline VAT & $61(16.7 \%)$ \\
\hline VAP & $159(43.56 \%)$ \\
\hline Total & $\mathbf{3 6 5}$ \\
\hline
\end{tabular}

Table.2 Sex distribution of VAT

\begin{tabular}{|l|c|c|}
\hline Gender & Number & \% \\
\hline Male & 42 & 69 \\
\hline Female & 19 & 31 \\
\hline Total & $\mathbf{6 1}$ & $\mathbf{1 0 0}$ \\
\hline
\end{tabular}

Table.3 Age wise distribution of VAT

\begin{tabular}{|l|c|c|}
\hline \multicolumn{1}{|c|}{ Age in years } & Number & $\mathbf{\%}$ \\
\hline$<1$ year & 13 & 21 \\
\hline 1-10year & 1 & 1 \\
\hline 11-20 year & 8 & 13 \\
\hline 21-30 year & 5 & 8 \\
\hline 31-40 year & 4 & 7 \\
\hline 41-50 year & 11 & 18 \\
\hline 51-60 year & 8 & 13 \\
\hline$>60$ year & 11 & 18 \\
\hline Total & $\mathbf{6 1}$ & $\mathbf{1 0 0}$ \\
\hline
\end{tabular}

Table.4 Distribution of cases according to intensive care units

\begin{tabular}{|l|c|c|}
\hline ICU's & Number & \% \\
\hline SICU & 18 & 30 \\
\hline MICU & 17 & 28 \\
\hline NICU & 11 & 18 \\
\hline CCU & 9 & 15 \\
\hline PICU & 6 & 10 \\
\hline Total & $\mathbf{6 1}$ & $\mathbf{1 0 0}$ \\
\hline
\end{tabular}


Table.5 Clinical spectrum of diseases of VAT

\begin{tabular}{|l|l|l|}
\hline Primary diagnosis & N & \% \\
\hline Closed head injury & 11 & 18 \\
\hline Birth asphyxia & 11 & 18 \\
\hline Op poisoning & 10 & 16 \\
\hline Hemorrhages & 8 & 13 \\
\hline Cerebrovascular accidents & 4 & 7 \\
\hline Snake bite & 4 & 7 \\
\hline Diabetic ketoacidosis & 3 & 5 \\
\hline Central nervous system infections & 2 & 3 \\
\hline Miscellaneous & 8 & 13 \\
\hline Total & 61 & 100 \\
& & \\
\hline
\end{tabular}

Table.6 Distribution of isolates with respect to duration of intubations and mechanical ventilation

\begin{tabular}{|c|c|c|c|c|c|c|}
\hline $\begin{array}{c}\text { No of days } \\
\text { after } \\
\text { intubations }\end{array}$ & P.aeruginosa & K.pneumonaie & A.baumannii & E.coli & C.freundii & S.aureus \\
\hline 2-3days & - & - & - & 2 & - & - \\
\hline 4-5 days & 1 & 1 & - & 2 & - & 1 \\
\hline 6-7 days & 1 & 5 & 1 & 1 & 2 & 2 \\
\hline 8-9 days & 9 & 7 & 4 & & 2 & 5 \\
\hline 10-11 days & 5 & 3 & 3 & & & \\
\hline 12-13 days & 3 & 1 & 5 & & & \\
\hline Total & $\mathbf{1 9}$ & $\mathbf{1 7}$ & $\mathbf{1 3}$ & $\mathbf{5}$ & $\mathbf{4}$ & $\mathbf{8}$ \\
\hline
\end{tabular}


Table.7 Association of predisposing risk factors with VAT

\begin{tabular}{|c|c|c|c|c|c|}
\hline Parameters & VAT N(\%) & VAP N(\%) & Total N(\%) & Chi square & $P$ value \\
\hline \multicolumn{6}{|l|}{ Prior antibiotic therapy } \\
\hline Yes & 34 (27.4) & 90 (72.6) & 124 (100.0) & 0.01345 & 0.9077 \\
\hline No & $27(28.1)$ & $69(71.9)$ & $96(100.0)$ & & \\
\hline \multicolumn{6}{|l|}{ Prior Imipenem Therapy } \\
\hline Yes & $13(35.1)$ & $24(64.9)$ & $37(100.0)$ & 1.218 & 0.2708 \\
\hline No & $48(26.2)$ & $135(73.8)$ & $183(100.0)$ & & \\
\hline \multicolumn{6}{|l|}{ Septic Shock } \\
\hline Yes & $3(27.3)$ & $8(72.7)$ & $11(100.0)$ & 0.001194 & 0.9724 \\
\hline No & $58(27.8)$ & $151(72.2)$ & $209(100.0)$ & & \\
\hline \multicolumn{6}{|c|}{ Congestive Cardiac Failure } \\
\hline Yes & $7(43.8)$ & $9(56.2)$ & $16(100.0)$ & 2.211 & 0.1371 \\
\hline No & $54(26.5)$ & $150(73.5)$ & $204(100.0)$ & & \\
\hline \multicolumn{6}{|l|}{ COPD } \\
\hline Yes & $7(46.7)$ & $8(53.3)$ & $15(100.0)$ & 2.881 & 0.08962 \\
\hline No & $54(26.3)$ & $151(73.7)$ & $205(100.0)$ & & \\
\hline \multicolumn{6}{|l|}{ Respiratory Failure } \\
\hline Yes & $9(15.5)$ & $49(84.5)$ & $58(100.0)$ & 5.86 & 0.0154 \\
\hline No & $52(32.1)$ & $110(67.9)$ & $162(100.0)$ & & \\
\hline \multicolumn{6}{|l|}{ Steroid Therapy } \\
\hline Yes & $11(16.9)$ & $54(83.1)$ & $65(100.0)$ & 5.374 & 0.0204 \\
\hline No & $50(32.3)$ & $105(67.7)$ & $155(100.0)$ & & \\
\hline \multicolumn{6}{|l|}{ IV Cannulation } \\
\hline Yes & 57 (29.0) & $140(71.0)$ & 197 (100.0) & 1.369 & 0.2426 \\
\hline No & $4(17.4)$ & $19(82.6)$ & $23(100.0)$ & & \\
\hline \multicolumn{6}{|l|}{ Diabetes Mellitus } \\
\hline Yes & $16(37.2)$ & $27(62.8)$ & $43(100.0)$ & 2.398 & 0.1215 \\
\hline No & $45(25.4)$ & $132(74.6)$ & $177(100.0)$ & & \\
\hline \multicolumn{6}{|l|}{ Hypertension } \\
\hline Yes & $6(30.0)$ & $14(70.0)$ & $20(100.0)$ & 0.05671 & 0.8118 \\
\hline No & $55(27.5)$ & $145(72.5)$ & $200(100.0)$ & & \\
\hline \multicolumn{6}{|l|}{ Malignancy } \\
\hline Yes & $2(50.0)$ & $2(50.0)$ & $4(100.0)$ & 1.009 & 0.3174 \\
\hline No & $59(27.3)$ & $157(72.7)$ & $216(100.0)$ & & \\
\hline
\end{tabular}

Table. 8 Causatic organisms of VAT

\begin{tabular}{|c|c|c|}
\hline Organisms & $N$ & $\%$ \\
\hline Pseudomonas aeruginosa & 19 & 29 \\
\hline Klebsiella pneumoniae & 17 & 26 \\
\hline Acinetobacter baumannii & 13 & 20 \\
\hline E.coli & 5 & 8 \\
\hline Citrobacter freundii & 4 & 6 \\
\hline Staphylococcus aureus & 8 & 12 \\
\hline Total & 66 & 100 \\
\hline
\end{tabular}


Table.9 Antimicrobial susceptible pattern of Gram negative bacteria isolated from Ventilator Associated Tracheobronchitis

\begin{tabular}{|c|c|c|c|c|c|c|c|c|c|c|c|c|c|c|c|c|c|c|c|c|}
\hline \multirow[b]{3}{*}{ Antibiotics } & \multicolumn{4}{|c|}{$\begin{array}{c}\text { Pseudomonas aeruginosa } \\
n=19\end{array}$} & \multicolumn{4}{|c|}{$\begin{array}{c}\text { Klebsiella pneumoniae } \\
n=17\end{array}$} & \multicolumn{4}{|c|}{$\begin{array}{c}\text { Acinetobacter } \\
\text { baumannii } n=13\end{array}$} & \multicolumn{4}{|c|}{$\begin{array}{c}E . c o l i \\
n=5\end{array}$} & \multicolumn{4}{|c|}{$\begin{array}{c}\text { Citrobacter } \\
\text { freundii } n=4\end{array}$} \\
\hline & \multicolumn{2}{|c|}{$\mathbf{S}$} & \multicolumn{2}{|c|}{$\mathbf{R}$} & \multicolumn{2}{|c|}{$\mathbf{S}$} & \multicolumn{2}{|c|}{$\mathbf{R}$} & \multicolumn{2}{|c|}{$\mathbf{S}$} & \multicolumn{2}{|c|}{$\mathbf{R}$} & \multicolumn{2}{|c|}{$\mathbf{S}$} & \multicolumn{2}{|c|}{$\mathbf{R}$} & \multicolumn{2}{|c|}{$\mathbf{S}$} & \multicolumn{2}{|c|}{$\mathbf{R}$} \\
\hline & $\mathbf{N}$ & $\%$ & $\mathbf{N}$ & $\%$ & $\mathbf{N}$ & $\%$ & $\mathbf{N}$ & $\%$ & $\mathbf{N}$ & $\%$ & $\mathbf{N}$ & $\%$ & $\mathbf{N}$ & $\%$ & $\mathbf{N}$ & $\%$ & $\mathbf{N}$ & $\%$ & $\mathbf{N}$ & $\%$ \\
\hline Amikacin & 6 & 31.6 & 13 & 68.4 & 7 & 41.2 & 10 & 58.8 & 3 & 23.1 & 10 & 76.9 & 3 & 60 & 2 & 40 & 1 & 25 & 3 & 75 \\
\hline Ofloxacin & 1 & 5.3 & 18 & 94.7 & 2 & 11.8 & 15 & 88.2 & 1 & 7.7 & 12 & 92.3 & 1 & 20 & 4 & 80 & 0 & 0 & 4 & 100 \\
\hline Gentamicin & 6 & 31.6 & 13 & 68.4 & 6 & 35.3 & 11 & 64.7 & 2 & 15.4 & 11 & 84.6 & 3 & 60 & 2 & 40 & 1 & 25 & 3 & 75 \\
\hline Ceftazidime & 3 & 15.8 & 16 & 84.2 & 5 & 29.4 & 12 & 70.6 & 0 & 0 & 13 & 100 & 3 & 60 & 2 & 40 & 1 & 25 & 3 & 75 \\
\hline Cefaperazone & 5 & 26.3 & 14 & 73.7 & 1 & 5.9 & 16 & 94.1 & 0 & 0 & 13 & 100 & 3 & 60 & 2 & 40 & 2 & 50 & 2 & 50 \\
\hline Cefiximeclavulanic acid & 4 & 21.1 & 15 & 78.9 & 5 & 29.4 & 12 & 70.6 & 2 & 15.4 & 11 & 84.6 & 2 & 40 & 3 & 60 & 0 & 0 & 4 & 100 \\
\hline Ciprofloxacin & 3 & 15.8 & 16 & & 7 & 41.2 & 10 & 58.8 & 2 & 15.4 & 11 & 84.6 & 1 & 20 & 4 & 80 & 0 & 0 & 4 & 100 \\
\hline Cefixime & 1 & 5.26 & 18 & 94.7 & 3 & 17.6 & 14 & 82.4 & 4 & 30.8 & 9 & 69.2 & 4 & 80 & 1 & 20 & 1 & 25 & 3 & 75 \\
\hline Cefotaxime & 4 & 21.1 & 15 & 78.9 & 1 & 5.9 & 16 & 94.1 & 1 & 7.7 & 12 & 92.3 & 3 & 60 & 2 & 40 & 1 & 25 & 3 & 75 \\
\hline Ceftriaxone & 5 & 26.3 & 14 & 73.7 & 2 & 12 & 15 & 88.2 & 1 & 7.7 & 12 & 92.3 & 2 & 40 & 3 & 60 & 1 & 25 & 3 & 75 \\
\hline Imipenem & 8 & 42.1 & 11 & 57.9 & 11 & 64.7 & 6 & 35.3 & 5 & 38.5 & 8 & 61.5 & 4 & 80 & 1 & 20 & 2 & 50 & 2 & 50 \\
\hline Meropenem & 6 & 31.6 & 13 & 68.4 & 10 & 58.8 & 7 & 41.2 & 4 & 30.8 & 9 & 69.2 & 4 & 80 & 1 & 20 & 1 & 25 & 3 & 75 \\
\hline Piperacillin+tazobactam & 8 & 42.1 & 11 & 57.9 & 9 & 52.9 & 8 & 47.1 & 6 & 46.2 & 7 & 53.8 & 4 & 80 & 1 & 20 & 3 & 75 & 1 & 25 \\
\hline Ceftriaxone+sulbactam & 7 & 36.8 & 12 & 63.2 & 10 & 58.8 & 7 & 41.2 & 7 & 53.8 & 6 & 46.2 & 4 & 80 & 1 & 20 & 3 & 75 & 1 & 25 \\
\hline Ceftazidime+tazobactam & 3 & 15.8 & 16 & 84.2 & 10 & 58.8 & 7 & 41.2 & 1 & 7.7 & 12 & 92.3 & 3 & 60 & 2 & 40 & 0 & 0 & 4 & 100 \\
\hline Sparfloxacin & 5 & 26.3 & 14 & 73.7 & 10 & 58.8 & 7 & 41.2 & 3 & 23.1 & 10 & 76.9 & 4 & 80 & 1 & 20 & 2 & 50 & 2 & 50 \\
\hline Gatifloxacin & 3 & 15.8 & 16 & 84.2 & 10 & 58.8 & 7 & 41.2 & 3 & 23.1 & 10 & 76.9 & 3 & 60 & 2 & 40 & 0 & 0 & 4 & 100 \\
\hline Cefipime+tazobactam & 7 & 36.8 & 12 & 63.2 & 10 & 58.8 & 7 & 41.2 & 0 & 0 & 13 & 100 & 4 & 80 & 1 & 20 & 0 & 0 & 4 & 100 \\
\hline
\end{tabular}


Table.10 Antimicrobial susceptible pattern of Gram positive bacteria isolated from Ventilator Associated Tracheobronchitis

\begin{tabular}{|c|c|c|c|c|}
\hline \multirow{2}{*}{ Antibiotics } & \multicolumn{4}{|c|}{ Staphylococcus aureus $\mathbf{n = 8}$} \\
\cline { 2 - 5 } & \multicolumn{3}{|c|}{ S } & \multicolumn{2}{|c|}{ R } \\
\cline { 2 - 5 } & $\mathbf{N}$ & $\%$ & $\mathbf{N}$ & $\%$ \\
\hline Penicillin & 1 & 12.5 & 7 & 87.5 \\
\hline Erythromycin & 4 & 50 & 4 & 50 \\
\hline Linezolid & 6 & 75 & 2 & 25 \\
\hline Azithromycin & 5 & 62.5 & 3 & 37.5 \\
\hline Cotrimoxazole & 2 & 25 & 6 & 75 \\
\hline Clindamycin & 5 & 62.5 & 3 & 37.5 \\
\hline Ciprofloxacin & 1 & 12.5 & 7 & 87.5 \\
\hline Levofloxacin & 5 & 62.5 & 3 & 37.5 \\
\hline Cefoxitin & 3 & 37.5 & 5 & 62.5 \\
\hline Doxycycline & 4 & 50 & 4 & 50 \\
\hline Vancomycin & 8 & 100 & 0 & \\
\hline Imipenem & 3 & 37.5 & 5 & 62.5 \\
\hline Meropenem & 3 & 37.5 & 5 & 62.5 \\
\hline Piperacillin+tazobactam & 5 & 62.5 & 3 & 37.5 \\
\hline & & & & \\
\hline & & & & \\
\hline
\end{tabular}

Table.11 Distribution of beta lactamases among different gram negative bacteria

\begin{tabular}{|c|c|c|c|c|c|c|c|}
\hline \multirow{2}{*}{ Organisms } & \multirow{2}{*}{$\begin{array}{c}\text { No } \\
\text { isolated }\end{array}$} & \multicolumn{2}{|c|}{ ES $\beta \mathbf{L}$} & \multicolumn{2}{|c|}{ MßL } & \multicolumn{2}{|c|}{ AmpC } \\
\hline & & $\mathbf{N}$ & $\%$ & $\mathbf{N}$ & $\%$ & $\mathbf{N}$ & $\%$ \\
\hline P.aeruginosa & 19 & 16 & 36 & 11 & 44 & 4 & 26 \\
\hline K.pneumoniae & 17 & 13 & 30 & 6 & 24 & 6 & 40 \\
\hline A.baumannii & 13 & 10 & 23 & 6 & 24 & 4 & 26 \\
\hline E.coli & 5 & 2 & 5 & 1 & 4 & 1 & 6 \\
\hline C. freundii & 4 & 3 & 7 & 1 & 4 & 0 & 0 \\
\hline Total & 58 & 44 & 76 & 25 & 43 & 15 & 26 \\
\hline
\end{tabular}




\section{Chart.1 Incidence of VAT}

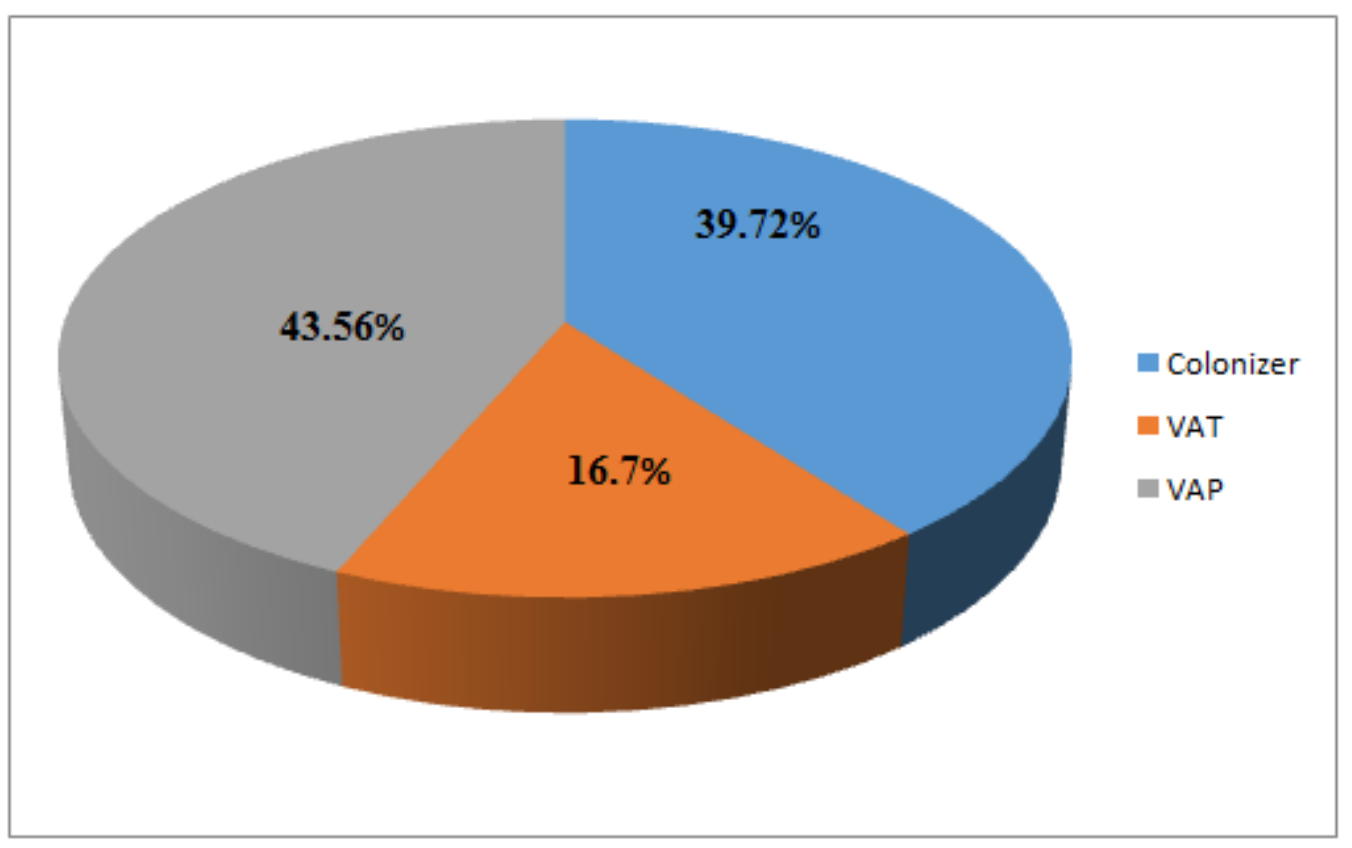

Chart.2 Distribution of sex of VAT

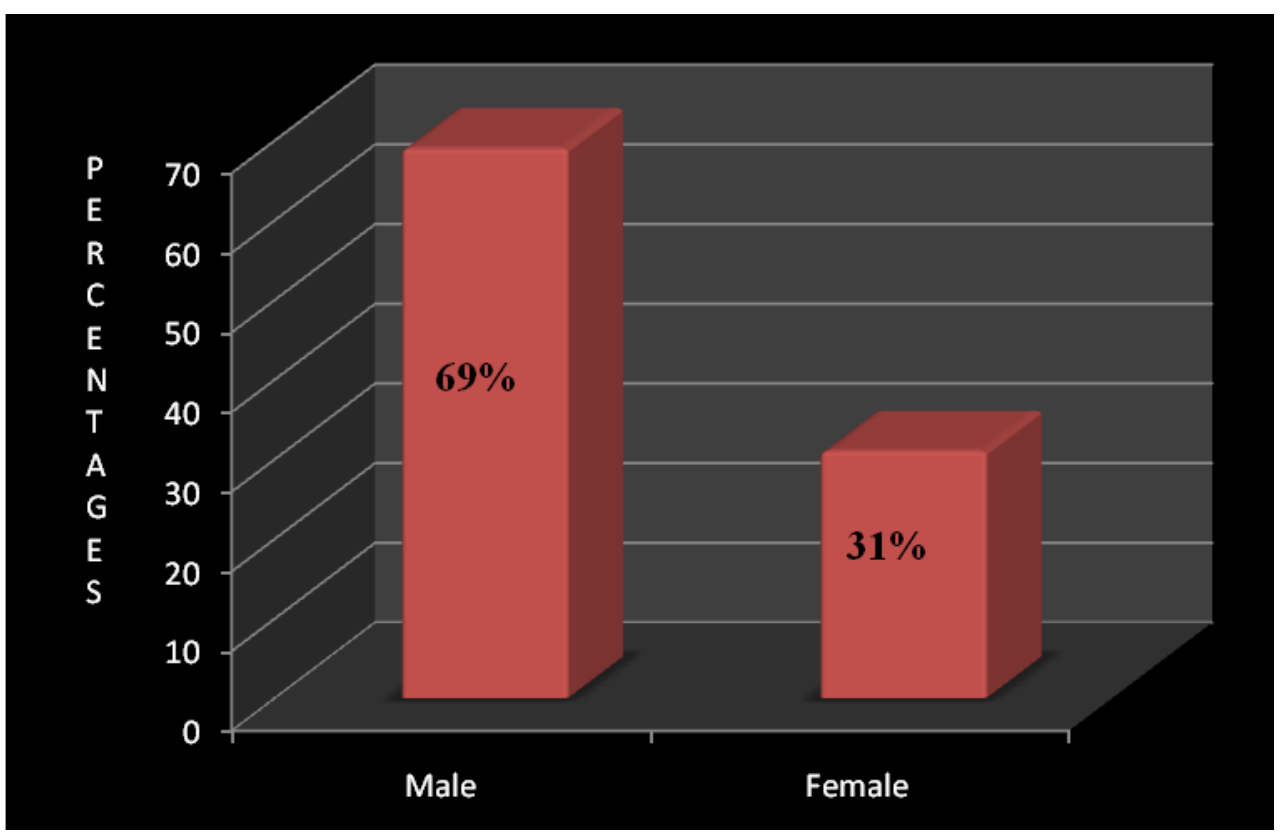




\section{Chart.3 Age wise distribution of VAT}

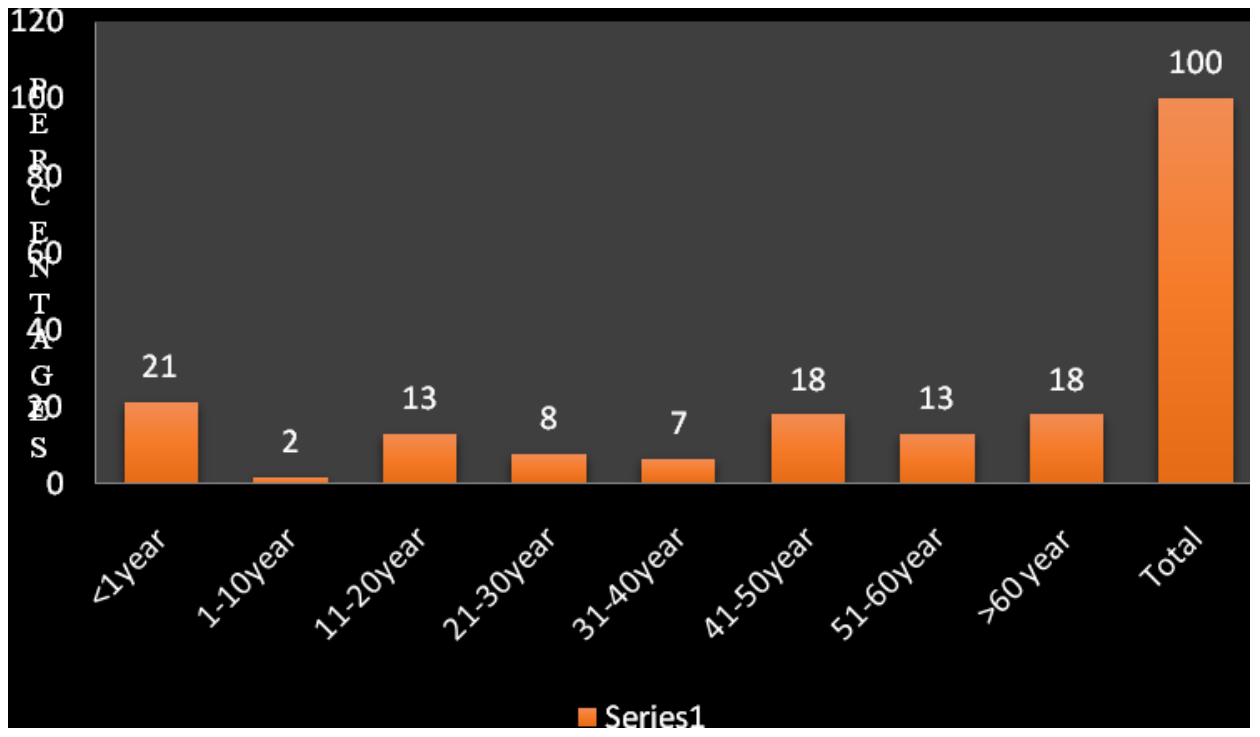

Chart.4 Distribution of cases according to intensive care units

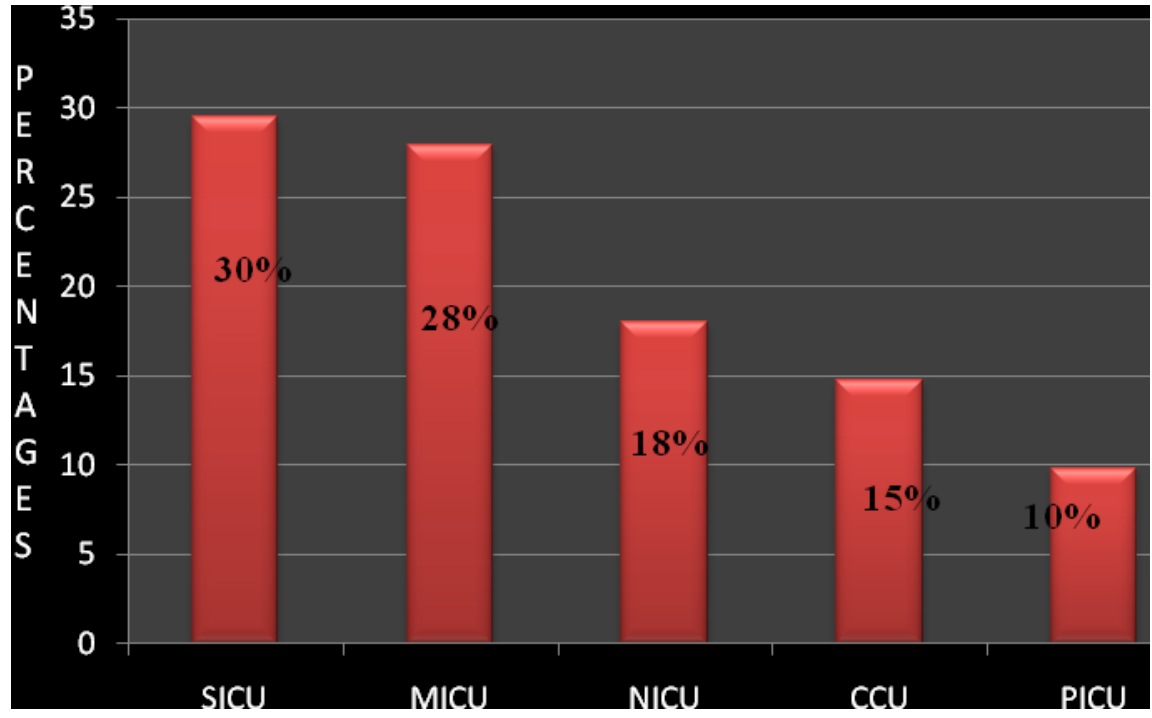




\section{Chart.5 Clinical spectrum of diseases of VAT}

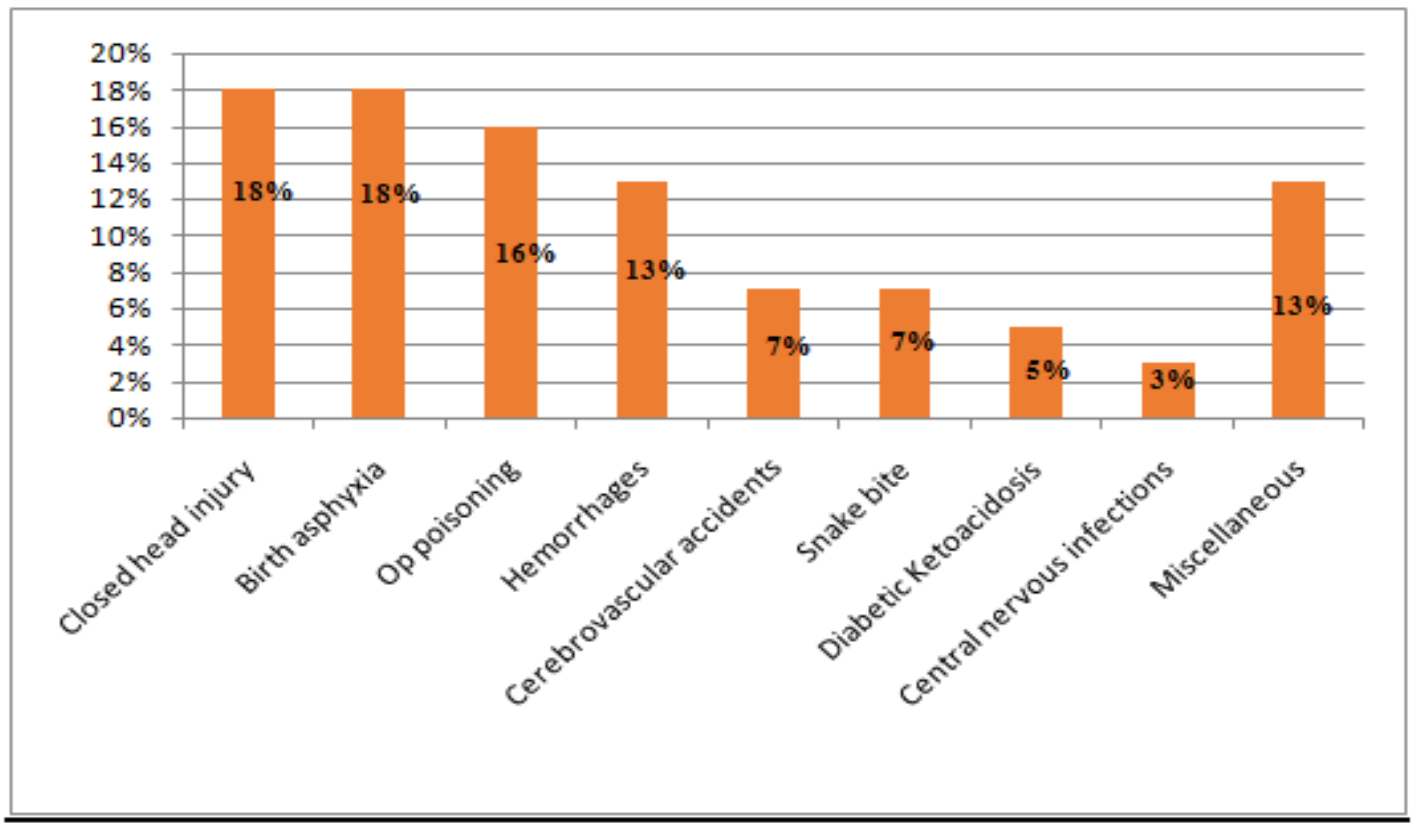

Chart.6 Causatic organisms of VAT

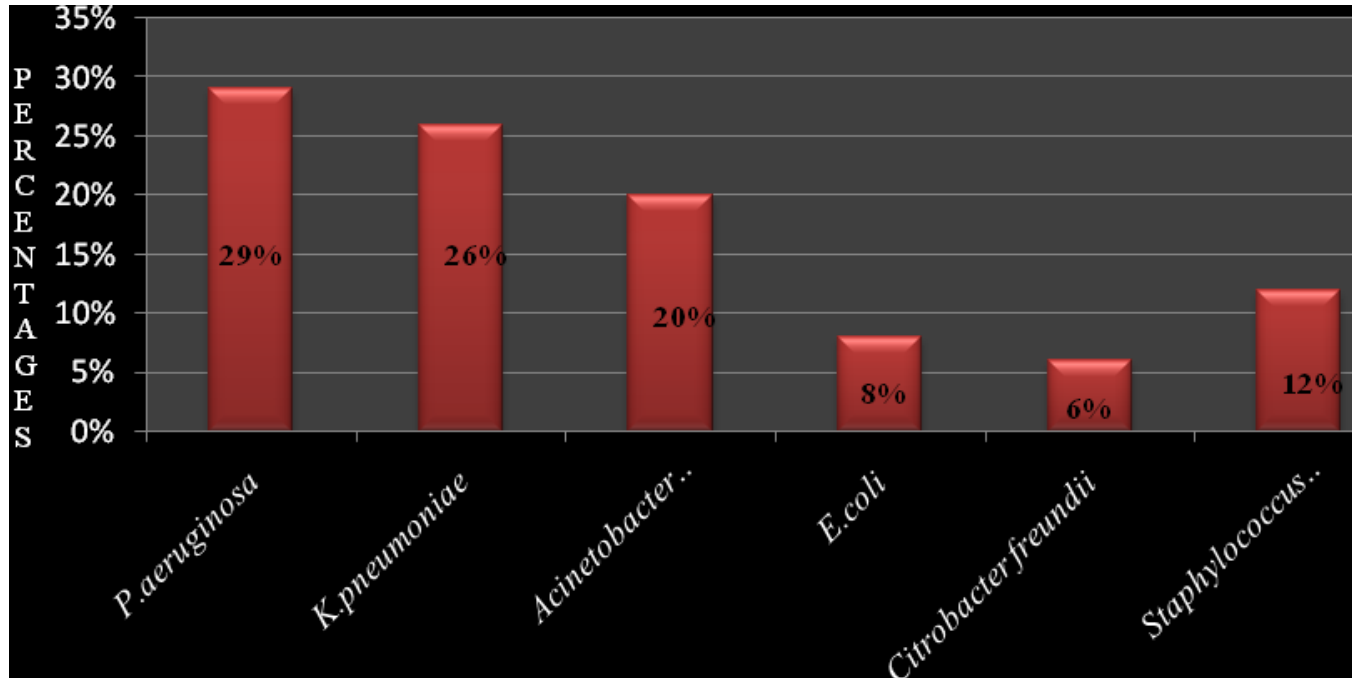

In contrary to Dey et al., (2007) where in $E$. coli and Klebsiella pneumoniae were predominate ES $\beta \mathrm{L}$ producers. An elevated level of drug resistance in Pseudomonas aeruginosa is because of the different mechanisms that include production of different types of $\beta$-lactamases primarily $\mathrm{ES} \beta \mathrm{L}, \quad \mathrm{AmpC}$ enzymes, and metallocarbapenemases, aminoglycoside-modifying enzymes, loss of porin proteins, and the presence of efflux pumps (Kumari et al., 2007).

In our study Klebsiella pneumoniae (25\%) was predominant AmpC producer which was in contrary to one of study conducted by Khanal et al., (2011) according to their study Acinetobacter species were the predominant 
AmpC producer. Among 8 Staphylococcus aureus isolated $62.5 \%$ of strains were Methicillin Resistant Staphylococcus aureus. The high incidence of MRSA in our study correlates with the studies done by Gupta et al., (2011).

Reason for increase in antimicrobial resistance is in appropriate initial empirical treatment. Combination therapy should be included in order to avoid antagonism of therapeutic mechanisms. Interventions that encourage evidence-based practices like routine hand hygiene, continuous aspiration of subglottic secretions, and semi recumbent positioning of patients can significantly reduce the rate of VAT.

\section{References}

Bouza, E., Pérez, A., Muñoz, P., et al. 2003. Cardiovascular infection study group. Ventilator-associated pneumonia after heart surgery: a prospective analysis and the value of surveillance. Crit Care Med., 31:1964-70.

Collee, J.G., Miles, R.S., Watt, B. 2006. Tests for the identification of bacteria. In: Collee JG, Marmion BP, Fraser AG, Simmons A, editors. Mackie \& McCartney Practical Medical Microbiology, $14^{\text {th }}$ edn. New York: Churchill Livingstone, p. 131-50.

Craven, D.E., Hjalmarson, K.I. 2010. Ventilator-associated tracheobronchitis and pneumonia: thinking outside the box. Clin Infect. Dis., 51: S59-66.

Cunnion, K.M., Weber, D.J., Broadhead, W.E., Hanson, L.C., Piper, C.F., Rutala, W.A. 1996. Risk factors for nosocomial pneumonia: comparing adult criticalcare populations. Am. J. Respir. Crit. Care Med., 153: 158-162.

Dallas, J., Skrupky, L., Abebe, N., et al. 2011. Ventilator-associated tracheobronchitis in a mixed surgical and medical ICU population. Chest, 139: 513-18.

Dey, A., Bairy, I. 2007. Incidence of multidrug -resistant organisms causing Ventilator associated pneumonia in a tertiary care hospital: A nine months' prospective study. Am. Thorac. Med., 2: 52-7.

Edmond, M.B., Ober, J.F., Weinbaum, D.L., et al. 1995. Vancomycin-resistant Enterococcus faecium bacteremia: risk factors for infection. Clin. Infect. Dis., 20: 1126-1133.

Goel, V., Hogade, S.A., Karadesai, S. 2012. Ventilator associated pneumonia in a medical intensive care unit: Microbial aetiology, susceptibility patterns of isolated microorganisms and outcome. Indian J. Anaesth., 56(6): 558-62.

Gupta, A., Agarwal, A., Mehrotra, S., Singh, A., Malik, S., Khanna, A. 2011. Incidence, risk stratification, antibiograms of pathogens isolated and clinical outcome of ventilator associated pneumonia. Indian J. Crit. Care Med., 15: 96-101.

Husni, R.N., Goldstein, L.S., Arroliga, A.C., et al. 1999. Risk factors for an outbreak of multi-drug resistant Acinetobacter nosocomial pneumonia among intubated patients. Chest, 115: 1378-82.

Khanal, S., Joshi, D.R., Bhatta, D.R., Devkota, U., Pokhrel, B.M. 2013. $\beta$ Lactamase-Producing MultidrugResistant Bacterial Pathogens from Tracheal Aspirates of Intensive Care Unit Patients at National Institute of Neurological and Allied Sciences, Nepal. ISRN Microbiol., 9: 847-852.

Kumari, H.B.V., Nagarathna, S., Chandramuki, A. 2007. "Antimicrobial resistance pattern among aerobic gramnegative bacilli of lower respiratory tract specimens of intensive care unit patients in a neurocentre," Indian J. Chest Dis. Allied Sci., 49(1): 19-22. 
Lee, K., Lee, W.G., Uh, Y., et al. 2003. "VIM- and IMP-type metallo- $\beta$ lactamase-producing Pseudomonas spp. and Acinetobacter spp. in Korean hospitals," Emerg. Infect. Dis., 9: 868871.

Lipovy, B., Rihová, H., Gregorova, N., et al. 2011. Epidemiology of ventilatorassociated tracheobronchitis and ventilator-associated pneumonia in patients with inhalation injury at the burn centre inbrno. Ann. Burns Fire Disasters, 114: 120-25.

Malacarne, P., Langer, M., Nascimben, E., et al. 2008. Building a continuous multicenter infections surveillance system in the intensive care unit: finding from initial date set of 9493 patients from 71 Italian intensive care units. Crit. Care Med., 36(4): 1105-13.

Martin-Loeches, I., Pobo, A. 2010. What Is New in Ventilator-Associated Tracheobronchitis? Clin. Pulm. Med., 17: 117-121.

Melsen, W.G., Rovers, M.M., Groenwold, R.H., et al. 2013. Attributable mortality of ventilator- associated pneumonia: a meta-analysis of individual patient data from randomised prevention studies. Lancet Infect. Dis., 13: 665-71.

Nseir, S., Di Pompeo, C., Pronnier, P., Beague, S., Onimus, T., Saulnier, F. 2002. Nosocomial tracheobronchitis in mechanically ventilated patients: incidence, aetiology and outcome. Eur. Respir. J., 20: 1483-9.

Nseir, S., Favory, R., Jozefowicz, E., et al. 2008. Antimicrobial treatment for ventilator-associated tracheobronchitis: a randomized controlled multicenter study. Crit. Care, 12: 62-65.

Palmer, L.B., Smaldone, G.C., Chen, J.J., et al. 2008. Aerosolized antibiotics and fet alventilator-associated tracheobronchitis in the intensive care unit. Crit. Care Med., 36: 2008-2013.

Richards, M.J., Edwards, J.R., Culver, D.H., Gaynes, R.P. 1999. Nosocomial infections in medical intensive care units in the United States. Crit. Care Med., 27: 887-92.

Rodríguez, A., Póvoa, P., Nseir, S., et al. 2014. Incidence and diagnosis of ventilator- associated tracheobronchitis in the intensive care unit: an international online survey. Critical Care, 18: R32.

Sadeka, S., Saida, A.E., Madkourb, A., Rabiea, A., Makya, Y. 2014. Ventilatorassociated tracheobronchitis in a surgical ICU population. Egypt $J$. Broncho., 8: 153-59.

Torres, A., Valencia, M. 2005. Does ventricular associated tracheobronchitis need antibiotic treatment. Critical Care, 9(3): 255-6.

Valencia Arango, M., Jorres Marti, A., Insausti Ordenana, J., et al. 2003. Diagnostic value of quantitavie cultures of endotracheal aspirate in Ventilator Associated Pneumonia: a multicenter study. Arch. Bronconeumol., 39(9): 394-9.

Vincent, J.L., Bihari, D.J., Suter, P., et al. 1995. The prevalence of nosocomial infection in intensive care units in Europe. JAMA, 274: 639-44.

\section{How to cite this article:}

Mayuri, K.S. 2017. Ventilator Associated Tracheobronchitis: Incidence, Etiology, Predisposing Risk Factors and Drug Resistance. Int.J.Curr.Microbiol.App.Sci. 6(7): 3864-3879. doi: https://doi.org/10.20546/ijcmas.2017.607.398 